\title{
ENVIRONMENTAL SYSTEMATICS AND ASTRONOMICAL REFRACTION, I*
}

\author{
J. A. HUGHES
}

U.S. Naval Observatory, Washington, D.C., U.S.A.

\begin{abstract}
The first results of a planned continuing investigation of astronomical refraction are reported in this paper. Pure and anomalous refraction are investigated using meteorological data and environmental models. Numerical methods based upon Chebyshev polynomials are developed. Applications are made to Winslow, Arizona (which is somewhat similar to El Leoncito, Argentina), and to results of PZT observations made in Washington, D.C.
\end{abstract}

\section{DISCUSSION}

Van Herk: The results for the constant of aberration from the PZT in Washington have always differed systematically from the one derived in Richmond. Could this yearly refraction term you mention be the cause of this discrepancy?

Teleki: Frankly speaking I don't know.

Klock: I would like to mention that Dr Hughes was encouraged to undertake this investigation by $\mathrm{Mr}$ F. P. Scott, who, after examining the first results from the El Leoncito Station, realised that the Pulkovo refraction table did not appear to cover the El Leoncito situation appropriately.

\footnotetext{
* The full text of this paper will appear in Publications de l'Observatoire Astronomique de Béograd, No. 18.
} 